\title{
Clinical Variants, Rates of Post-Operative Recurrence and Malignant Transformation of Sino-Nasal Inverted Papilloma
}

\author{
Israa M. Qadmi ${ }^{*}$, Alaa Q. Mandeel1', Jehad H. Hammad'1, Reem J. Radhi'², Sayed Ali I. Al Mahari ${ }^{3}$ \\ ${ }^{1}$ Department of Otorhinolaryngology, Salmaniya Medical Complex, Manama, Kingdom of Bahrain \\ ${ }^{2}$ Department of Radiology, Salmaniya Medical Complex, Manama, Kingdom of Bahrain \\ ${ }^{3}$ Department of Pathology, Salmaniya Medical Complex, Manama, Kingdom of Bahrain \\ Email: ^IMohamed1@health.gov.bh, Alo0oa_89@hotmail.com,Dr.Jehad.hammad@gmail.com,Dr.rmaki@outlook.com, \\ Sayed.almahari@gmail.com
}

How to cite this paper: Qadmi, I.M., Mandeel, A.Q., Hammad, J.H., Radhi, R.J. and Al Mahari, S.A. (2021) Clinical Variants, Rates of Post-Operative Recurrence and Malignant Transformation of Sino-Nasal Inverted Papilloma. International Journal of Otolaryngology and Head \& Neck Surgery, 10, 497-510.

https://doi.org/10.4236/ijohns.2021.106044

Received: August 7, 2021

Accepted: October 18, 2021

Published: October 21, 2021

Copyright $\odot 2021$ by author(s) and Scientific Research Publishing Inc. This work is licensed under the Creative Commons Attribution International License (CC BY 4.0).

http://creativecommons.org/licenses/by/4.0/ (c) (i) Open Access

\begin{abstract}
Background: Inverted Papilloma (IP) is the most common benign neoplasms arising from the mucosal lining of the of the Sino-Nasal tract with single or multifocal attachment sites. The high propensity to recur, local aggressive behavior and possibility of malignant transformation attract considerable interest. Objective: To assess the factors affecting Sino-nasal IP, malignant transformation rate, and post-operative recurrence rate. Methods: A retrospective study was carried out on all cases diagnosed as Sino-Nasal Papilloma between January 2010 and December 2020 at Salmaniya Medical Complex, Bahrain. Data gathered from medical records were analyzed using SPSS. A total of 49 Sino-Nasal Papilloma cases were recorded of which 37 were IP. Factors affecting Sino-Nasal IPs are presented. Results: Sino-Nasal IP was recorded in 37 cases, composed of 28 males and 9 females with first presentation average age of 45.86 years. These involved 20 cases in the left side, 14 in the right side and 3 were bilateral. Recurrence in males and females was found to be $35.7 \%$ and $33 \%$, respectively, with an average of 12.6 months. The symptoms include nasal blockage (97.3\%), epistaxis and postnasal drip (13.5\% each), headache (8.1\%) and hyposmia and rhinorrhea (5.4\%, each). The main recurrence was at stage T2 (60.5\%), while in smokers (26.7\%) and non-smokers (50\%). Malignant transformation occurred in one patient only (2.6\%). Conclusion: IP is the most common type of SNP with male predominance. The recurrence rate is high with an average of a year and the malignant transformation occurred in $2.6 \%$ of the cases.
\end{abstract}

\section{Keywords}

Bahrain, Clinical Risk Factors, Malignant Transformation, Sino-Nasal 
Inverted Papilloma, Smoking, Salmaniya Medical Complex

\section{Introduction}

According to the World Health Organization (WHO), Sino-Nasal Papillomas (SNP) are classified in three subtypes: exophytic, oncocytic and inverted. The latter is the most prevalent subtype, followed by exophytic, while oncocytic papilloma is the least common [1].

Sino-Nasal Inverted Papilloma (SNIP) represents the most common benign epithelial neoplasm that occurs in the sinonasal tract [2]. These originate from the Schneiderian epithelium that lines the nose and paranasal sinuses [3] [4], with an incidence of $0.75-0.5 / 100,000$ annually [5]. It accounts for $0.5 \%-4 \%$ of all Sino-nasal neoplasms [6]. Other names given to this tumor include epithelial papilloma, Ringertz's tumor, transitional cell papilloma, villiform cancer and Ewing's papilloma [7].

Although the demographic, morphological and clinical characteristics of IP have been well described, the etiology, risk factors and potential role in the recurrence, especially for smoking, occupational exposure to welding, organic solvents, allergens and the role of human papilloma virus (HPV) still remain a topic of controversy and are yet to be confirmed.

Recent studies by Kashima et al. [8], McKay et al. [9], Cheung et al. [10], and Hwang et al. [11] have all suggested and implicated that HPV plays not only an active role in malignant transformation, but also in its recurrence. On the contrary, despite the number of studies implicating HPV in the pathogenesis of IP, there are yet a number of studies documenting otherwise, such as the study by Karft et al. [12] and the more recent study by Mohajeri et al. [13].

Malignant transformation and recurrence of SNIP have been implicated in cases with high and low-risk HPV subtypes; in particular, HPV types 6, 11, 16, 18 [14] and epidermal growth factor receptor (EGFR) 1 [15] [16]. Moreover, HPV types 16 and 18 were found to increase the risk of IP malignant transformation into Squamous Cell Carcinoma (SCC) [17], with disease incidence ranging from $2 \%$ 27\% [18]. Smoking on the other hand, has not been implicated in the development of IP, but has shown to contribute in recurrence and malignant potential [19].

Clinico-pathologically, SNIP typically involves the lateral nasal wall and/or the paranasal sinuses, usually arising as a unilateral single lesion causing nasal obstruction. Other presenting non-specific symptoms may be rhinorrhea, postnasal drip, headache, epistaxis and hyposmia [20].

IP most frequently affects people in their fifth to seventh decades of life and is three times more frequent in males than females [21].

Although no universally accepted system is available, the Krouse classification has been widely used due to its ease of implementation as a tool for staging the 
disease [22].

Historically, the "gold standard" surgical approach employed across was medial maxillectomy via lateral rhinotomy or midfacial degloving procedure [23] [24]. Recently, however, endoscopic approach/endoscopic resection procedure has been increasingly favored because it obviates the morbidity of a surgical external approach [25]. Alternatively, some surgeons have combined the endonasal operation (endoscopic) with an external (open) procedure [26].

SNIP attracts considerable interest because it is highly aggressive, has a high propensity to recur (up to 78\%) [27], and is significantly associated with malignant transformation (10\% - 15\% cases) most frequently to SCC [28] [29].

The aim of the present study is to assess factors related to SNIP, malignant transformation rate, and the post-operative recurrence rate.

\section{Methodology}

A retrospective single-centered descriptive study was carried out on all patients diagnosed with SNP whom underwent surgery in the Department of Otolaryngology, Head and Neck Surgery at Salmaniya Medical Complex, Kingdom of Bahrain. The study spanned over a total period of 11 years between January 2010 and December 2020. The inclusion criteria consisted of all patients with diagnosed symptoms of nasal blockage, epistaxis, postnasal drip, headache, hyposmia and rhinorrhea. In addition, the inclusion criteria took into consideration all histo-pathologically confirmed cases of SNIP by Pathology Department at Salmaniya Medical Complex, and patients who underwent surgical intervention in our primary center only. The exclusion criteria contemplated patients with incomplete histopathology reports or underwent surgery in other centers and patients with missing and/or insufficient data. Furthermore, SNP of exophytic and/ or oncocytic origins were excluded altogether from the present study.

Accessible data was extracted from the medical records department, National Health Information System (I-Seha) and Laboratory Information System (LIS) of the Ministry of Health, Kingdom of Bahrain during the last 11 years. A total of 49 cases of SNP were identified and recorded, of which 10 were exophytic, 2 were oncocytic resulting in exclusion from our study, while the remaining were of the SNP inverted type. Thus, 37 cases were considered our study sample (Table 1). However, one case was initially dismissed due to insufficient data.

Clinical variables including age, gender, presenting symptoms, anatomical site

Table 1. Types and numbers of Sino-Nasal Papilloma.

\begin{tabular}{ccc}
\hline Type of Sino-Nasal Papilloma (SNP) & Number of Cases & (\%) of Cases \\
\hline Exophytic & 10 & 20.4 \\
Oncocytic & 20 & 40.8 \\
Inverted & 37 & 75.5 \\
Total & 49 & 100 \\
\hline
\end{tabular}


and side of tumors, rates of malignant transformation and post-operative recurrence, tobacco exposure and HPV (Human Papilloma Virus) testing were all documented. In addition, we opted to stage the tumors as per the universal Krouse classification system [22] to obtain relevance between the stage of tumors and likelihood of their recurrence and the patients were followed up at different intervals for not less than 12 months.

Calculations were performed in Microsoft Excel, and data was entered and analyzed using IBM SPSS Statistics (Version 26). As for the correlation between the Krouse staging and the recurrence rate, Chi-square test was used.

An official ethical and scientific approval from the Institutional Ethical Review Board, Ministry of Health, Kingdom of Bahrain, was attained in March 2021 (Approval No. 50210321). Furthermore, a verbal consent was obtained from the patients.

\section{Results}

Between 2010 and 2020, 49 cases of Sino-Nasal Papilloma were identified. All cases of SNIP were included which accounted for 37 (75.5\%) cases. Other types of SNP were excluded (Table 1).

The study sample composed of 28 males (75.7\%) and 9 females (24.3\%), with a male to female ratio at 3:1 (Table 2).

Age at presentation varied from 15 - 84 years, while the most common age group was between 45 - 54 years with an average of 45.86 years. A mean age of 45.04 and 48.44 was found in males and females, respectively. Recurrence varied among all age groups with no clear pattern.

Sino-Nasal IPs involved the left side in 20 cases (54.1\%), while 14 cases (37.8\%) involved the right side and 3 cases $(8.1 \%)$ revealed bilateral at time of presentation (Table 3). In terms of SNP recurrence, 13 cases (35.1\%) had recurrence of

Table 2. Gender and percentage of Sino-Nasal Papilloma.

\begin{tabular}{ccc}
\hline Gender & Number of Cases & $(\%)$ of Cases \\
\hline Male & 28 & 75.7 \\
Female & 9 & 24.3 \\
Total & 37 & 100 \\
\hline
\end{tabular}

Table 3. Sino-Nasal Papilloma recurrence side in patients.

\begin{tabular}{ccccc}
\hline & \multicolumn{4}{c}{ Recurrence } \\
\hline Side & No & Yes & Total & $(\%)$ of Cases \\
\hline Left & 12 & 8 & 20 & 54.1 \\
Right & 10 & 4 & 14 & 37.8 \\
Bilateral & 2 & 1 & 3 & 8.1 \\
Total & 24 & 13 & 37 & 100 \\
\hline
\end{tabular}


the disease after undergoing endoscopic surgical procedures and recurrence was within an average of 12.6 months (Table 3 ).

All cases involved the nasal cavity, while 11, 27, 16, and 2 cases extended to the frontal, maxillary, ethmoidal, and sphenoidal sinuses, respectively.

Gender wise, post-operative recurrence of SNIP was found to be approximately equivalent in males and females with $35.7 \%$ and $33 \%$, respectively, showing no predilection to any gender (Figure 1(A)).

Out of the 37 cases, 22 were smokers $(59.41 \%)$ and 13 were non-smokers $(40.54 \%)$.

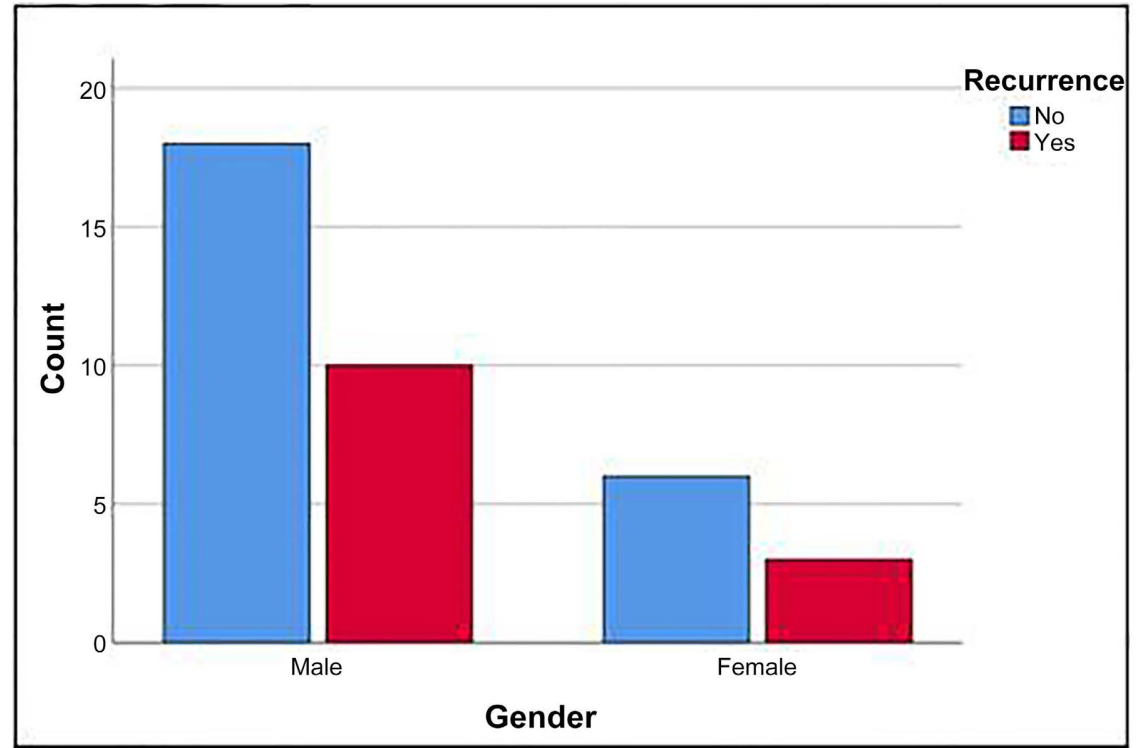

(A)

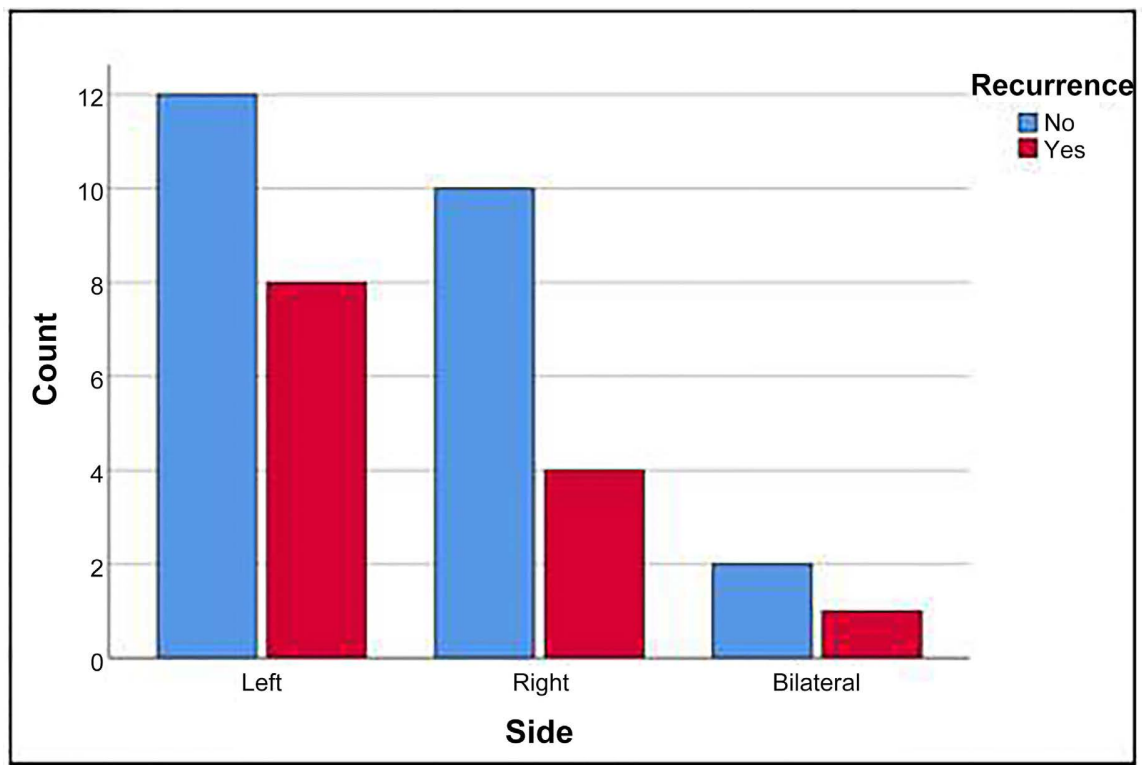

(B)

Figure 1. Bar charts comparing the recurrences of the ISNPs with gender (A) difference and side of the tumor accordingly 
Of the 13 cases with post-operative recurrence, 8 cases $(61.5 \%)$ showed recurrence in the left side, 4 cases $(30.8 \%)$ in the right side and 1 case $(7.7 \%)$ showed bilateral recurrence (Figure 1(B)).

The main presenting symptoms associated with SNIP were nasal blockage in 36 cases $(97.3 \%)$, followed by epistaxis and postnasal drip in five cases $(13.5 \%$ each), headache in 3 cases $(8.1 \%)$ and hyposmia and rhinorrhea in two cases only (5.4\% each) (Table 4).

All patients were managed with a pure endoscopic sinus approach and no adjunctive external surgical approaches were required or applied.

The Krouse classification was applied to all SNIP cases. Four patients (10.81\%) were classified as stage T1, twenty-three patients (62.16\%) were classified as stage T2, nine patients $(24.32 \%)$ were classified as stage T3, and one patient $(2.70 \%)$ was classified as stage T4 (Table 4). Most post-operative recurrences were found to be in patients earlier categorized as stage T2. No statistical significance was determined between Krouse classification and recurrence rate at $P$-value of 0.146 .

Malignant transformation occurred in one patient only $(2.6 \%)$. The patient Table 4. Demographic and clinical data of Sino-Nasal Papilloma.

\begin{tabular}{|c|c|c|}
\hline Parameter & Number of Cases & (\%) of Cases \\
\hline \multicolumn{3}{|l|}{ Age (Year) } \\
\hline$\geq 45$ & 22 & 59.46 \\
\hline$<45$ & 15 & 40.54 \\
\hline \multicolumn{3}{|l|}{ Smoking } \\
\hline Smoker & 22 & 59.41 \\
\hline Nonsmoker & 15 & 40.54 \\
\hline \multicolumn{3}{|l|}{ Main Presenting Symptoms } \\
\hline Nasal Blockage & 36 & 97.30 \\
\hline Epistaxis \& Postnasal Drip & 5 & 13.51 \\
\hline Headache & 3 & 8.11 \\
\hline Hyposmia \& Rhinorrhea & 2 & 5.41 \\
\hline \multicolumn{3}{|l|}{ Side } \\
\hline Left & 20 & 54.05 \\
\hline Right & 14 & 37.84 \\
\hline Bilateral & 3 & 8.11 \\
\hline \multicolumn{3}{|l|}{ Krouse Classification } \\
\hline Stage 1 & 4 & 10.81 \\
\hline Stage 2 & 23 & 62.16 \\
\hline Stage 3 & 9 & 24.32 \\
\hline Stage 4 & 1 & 2.70 \\
\hline
\end{tabular}


was a 48 year old male, smoker, who presented with nasal blockage and occasional left sided epistaxis. Primary lesion was left sided, and it extended from the nasal cavity to the ethmoidal, frontal and maxillary sinuses, and was classified as Krouse stage T3. The patient was initially diagnosed in 2013 and underwent endoscopic sinus surgery with post-operative chemotherapy and histopathology confirmed the diagnosis of squamous cell carcinoma (SCC). After that, he developed multiple recurrences, in which the first was in 2016 and the second was in 2018. A pan CT was taken for the patient for staging purposes, and MRI for further investigation. No distant metastasis was found (Figure 2).

Human Papilloma Virus analysis was not done for any of the cases in our center, except for one patient who had positive history of recurrence of disease within a one-year interval. That was one of the limitations we came across in our study for determination of relevance of positive HPV result with recurrence of the disease.

\section{Discussion}

IP is the most common diagnosed subtype of Sino-Nasal Papilloma, accounting
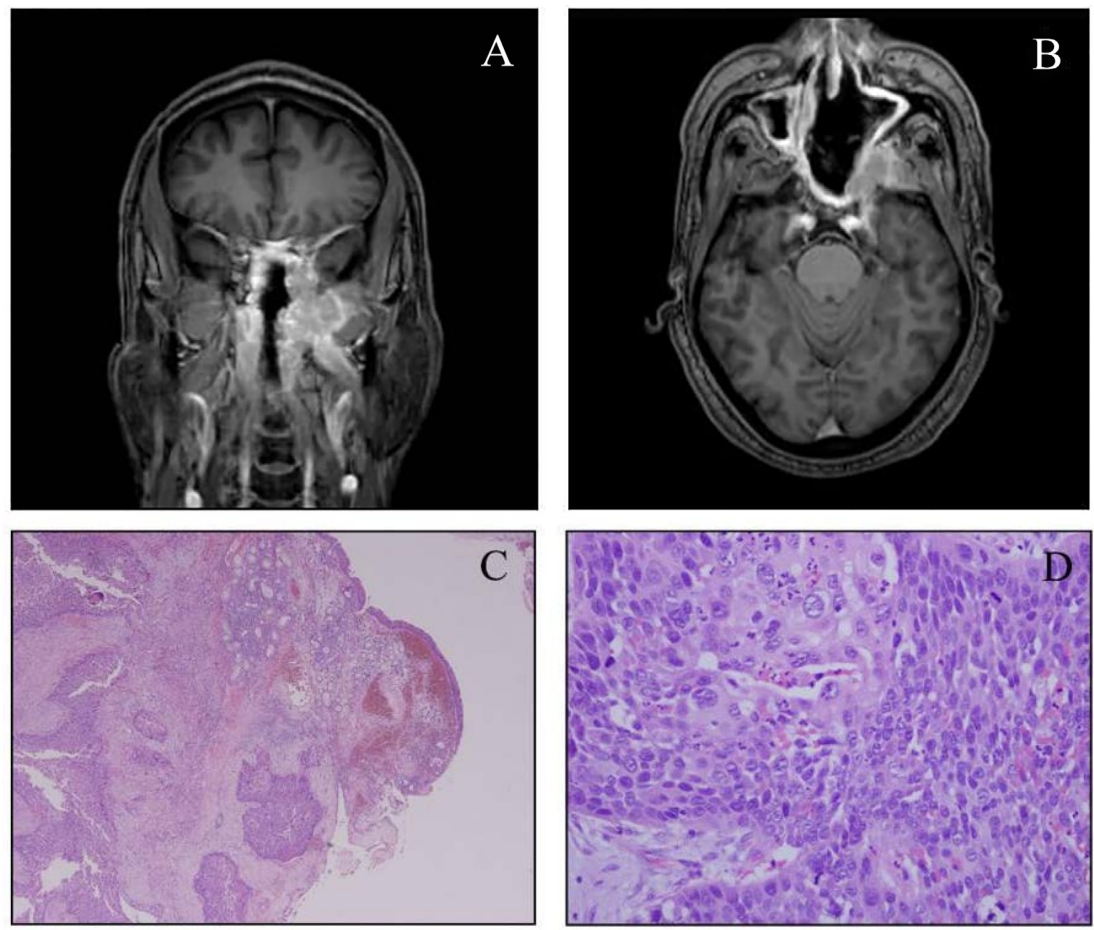

Figure 2. (A) Coronal T1 post contrast. Heterogenously mildly enhancing residual soft tissue mass lesion centered within the left ptyrogoid plate and nasopharangeal wall showing extension into the masticator space and medical ptyrogoid muscle; (B) Axial T1 post contast. Intracranial and extra axial extension of the tumor is noted reaching into cavernous sinus anteriorly with erosive changes of the left greater wing of the sphenoid. (C and D) A fragment of sinonasal mucosa lined focally by respiratory type epithelium; The underlying submucosa is infiltrated by nests of moderately pleomorphic cells with eosinophilic cytoplasm and distinct nucleoli. Multiple foci of necrosis and mitotic figures are noted. 
for more than $50 \%$ of total Sino-Nasal Papillomas worldwide. The exophytic subtype and least commonly the oncocytic subtype in literature [1] follow. Our study showed 49 cases of Sino-Nasal Papilloma; of which 37 cases (75.5\%) were identified as inverted, 10 cases (20.4\%) were exophytic and two cases only (4\%) were oncocytic (Table 1). This was concordant with current literature [28] [29].

The mean age for SNIP patients was 45.86 years and male: female ratio of 3:1 was found in our study (Table 2). This was consistent with current literature that stated SNIP has preponderance in males. However, unlike most literature, our patients mean age was in the fourth decade and not the fifth decade of their lives [30] [31].

In terms of recurrence of disease, 13 cases (35.1\%) had recurrence of the disease after undergoing endoscopic surgical procedures (Table 3 ) and recurrence was within an average of 12.6 months. The recurrence rate of IPs in literature was shown to be between $15 \%-20 \%$ [29] [32]. There is still much controversy regarding the causative agents and the roles of different factors on the recurrence and persistence of IPs. In some of the literature, recurrence rate is as high as 78\% [27]. However, in our study it was moderate in recurrence (35.1\%).

In our study, Sino-Nasal IPs involved the left side in 20 cases $(54.1 \%)$, while 14 cases $(37.8 \%)$ involved the right side and 3 cases (8.1\%) were bilateral at time of presentation (Table 3). Of those 13 cases with recurrence, 8 cases $(61.5 \%)$ recurred in the left side, 4 cases (30.8\%) in the right side and one case (7.7\%) bilaterally (Figure $1(B)$ ). The side of Sino-Nasal IP was not statistically related to the rate of recurrence or persistence of IPs, while lesion localization was of relative significance.

All cases involved the nasal cavity, while 11, 27, 16, and 2 cases extended to the frontal, maxillary, ethmoidal, and sphenoidal sinuses, respectively. Also in accordance with other literature [29] [32], IP arising from the maxillary sinus, nasal cavity and ethmoidal sinuses were most frequently found. In our study, the most common was the nasal cavity followed by the maxillary sinus. The frontal sinus however, was high in prevalence in our study, which was contradictive with literature [33] [34] [35]. Recurrence was found to be in 13 cases $(35.1 \%)$ of one primarily in the nasal cavity, 5 cases (45.5\%) in the frontal sinus, 7 cases (43.75\%) in the ethmoidal sinus, and 10 cases $(37 \%)$ in the maxillary sinus and none in the sphenoid sinuses. This may be explained by the limitation of surgical accessibility to remove all tumors or due to surgeon discrepancies [36] [37] [38] [39] [40].

In recent literature, endoscopic surgery is a very effective and accurate treatment method for patients with IP [39]. In a study by Gil et al., the calculated recurrence rate was $13.3 \%$ without significant differences between the endoscopically treated patients compared to patients undergoing combined or open surgery [39]. In our study, all patients were managed by pure endoscopic methods.

The main presenting symptoms associated with SNIP were nasal blockage (Table 4) in 36 cases (97.3\%), as it was in literature [41] [42], followed by epistaxis and post nasal drip in 5 cases (13.5\% each), headache in 3 cases $(8.1 \%)$ and 
hyposmia and rhinorrhea in 2 cases (5.4\% each).

The clinical staging of IPs has been identified using the Krouse classification system, which is the most widely used staging system currently [43] [44], while certain literature has emphasized on the role of IP stage with IP recurrence [45] [46]. In a recent study [47], the authors did not identify an association between the Krouse stage and incidence of recurrence, which was compatible with the result of our study. In our study, 4 patients (10.81\%) were classified as stage T1, 23 patients $(62.16 \%)$ were classified as stage T2, 9 patients (24.32\%) were classified as stage T3, and 1 patient (2.70\%) was classified as stage T4 (Table 4). Most recurrences were found to be in patients previously found with stage T2, and a statistical $p$ value of 0.146 was determined, which was statistically insignificant for establishing a correlation between Krouse classification and recurrence rate.

In our study, only one patient underwent malignant transformation and was confirmed to be squamous cell carcinoma. This comprised $2.6 \%$ of the total study sample and was consistent with current literature that suggested the incidence of malignancy varied and ranged from $2 \%-27 \%$ [19]. Most commonly, SCC was associated with malignant transformation of IPs, however, other types of carcinoma like adenocarcinoma, mucoepidermoid carcinomas, nasal undifferentiated carcinomas, small cell carcinomas and NOS (not specifically specified) were associated with IPs [44]. Although it was reported that progression of IPs to SCC was associated with presence of HPV in literature [19] [47]. Mohajeri et al. found that HPV was not supported as an etiological factor in IP development or its progression to SCC [31]. Unfortunately, in our study, we did not have sufficient HPV testing, and that was considered as one of the limitations of this study. Thus, further research is required to establish an association between HPV infections and IP recurrence or progression to SCC.

Smoking and exposure to tobacco was reported in $40.5 \%$ of our study, with recurrence rate of $26.7 \%$. While, nonsmokers in our study were reported to be $59.5 \%$ with a recurrence rate of $50 \%$. This demonstrated that tobacco exposure was not a significant variable in terms of recurrence of the disease in this study sample. However, this is contradicted in literature that has identified smoking as an important risk factor of IP recurrence [44] [48].

Other factors have been documented regarding the role of genetic alterations such as p53, p21, p16, inflammatory genes, anti-apoptotic factors and intercellular adhesion molecules into SNIP malignant transformation [49]. Keles et al. [48] revealed reduced level of p27 expression correlated with increased cell proliferation in Sino-Nasal tumors, while variable p21 and p53 expressions were detected in both benign and malignant tumors of the Sino-Nasal epithelium [48].

\section{Conclusion}

This retrospective study summarized our findings in terms of clinical characteristics, post-operative recurrence rate, malignant transformation and other factors affecting the rate of recurrence. The earlier the time of diagnosis and the 
earlier the Krouse staging at diagnosis, the more accurate and complete the surgical intervention would be. Rates of recurrence minimize with thorough resection of tumors at initial surgery. One of the limitations of this study was the missed long-term follow-up of these patients to detect recurrence in a timely manner. Further studies are required for identification of risk factors and certain etiologies in the pathogenesis of Sino Nasal Inverted Papilloma as there are many controversies in the etiology of such papillomas.

\section{Acknowledgements}

A special thanks to the pathology and radiology department members for providing the patients data. We extend our thanks to Training Directorate, Ministry of Health, Kingdom of Bahrain, for their support and encouragement.

\section{Ethical Consideration}

Ethical approval submitted.

\section{Authors' Contributions}

All authors were involved with the conception and design of the study, analysis and interpretation of the data, and have approved the final manuscript.

\section{Conflicts of Interest}

The authors declare no competing interests.

\section{References}

[1] Barnes, L. (2002) Schneiderian Papillomas and Nonsalivary Glandular Neoplasms of the Head and Neck. Modern Pathology, 15, 279-297. https://doi.org/10.1038/modpathol.3880524

[2] Xu, B. (2021) Sinonasal Papilloma. https://www.pathologyoutlines.com/topic/nasalsinonasalpapilloma.html

[3] Yasumatsu, R., Nakashima, T. and Komune, S. (2013) Sinonasal Inverted Papilloma: A Current Review. Fukuoka Acta Medica, 104, 199-204.

[4] Karkos, P.D., Fyrmpas, G., Carrie, S.C. and Swift, A.C. (2006) Endoscopic versus Open Surgical Interventions for Inverted Nasal Papilloma: A Systematic Review. Clinical Otolaryngology, 31, 499-503. https://doi.org/10.1111/j.1365-2273.2006.01333.x

[5] Barnes, L., Verbin, R. and Gnepp, D. (1985) Diseases of the Nose, Paranasal Sinuses and Nasopharynx. In: Barnes, L., Ed., Surgical Pathology of the Head and Neck, Marcel Dekker, New York, 403-416.

[6] Myers, E.N., Fernau, J.L., Johnson, J.T., Tabet, J.C. and Barnes, E.L. (1990) Management of Inverted Papilloma. The Laryngoscope, 100, 481-490. https://doi.org/10.1288/00005537-199005000-00008

[7] Bielamowicz, S., Calcaterra, T.C. and Watson, D. (1993) Inverting Papilloma of the Head and Neck: The UCLA Update. Otolaryngology-Head and Neck Surgery, 109, 71-76. https://doi.org/10.1177/019459989310900113

[8] Kashima, H.K., Kessis, T., Hruban, R.H., Wu, T.C., Zinreich, S.J. and Shah, K.V. (1992) Human Papillomavirus in Sinonasal Papillomas and Squamous Cell Carci- 
noma. The Laryngoscope, 102, 973-976.

https://doi.org/10.1288/00005537-199209000-00003

[9] McKay, S.P., Gre'goire, L., Lonardo, F., Reidy, P., Mathog, R.H. and Lancaster, W.D. (2005) Human Papillomavirus (HPV) Transcripts in Malignant Inverted Papilloma Are from Integrated HPV DNA. The Laryngoscope, 115, 1428-1431. https://doi.org/10.1097/01.mlg.0000168091.50584.b4

[10] Cheung, F.M., Lau, T.W., Cheung, L.K., Li, A.S., Chow, S.K. and Lo, A.W. (2010) Schneiderian papillomas and Carcinomas: A Retrospective Study with Special Reference to p53 and p16 Tumor Suppressor Gene Expression and Association with HPV. Ear, Nose \& Throat Journal, 89, E5-E12.

https://doi.org/10.1177/014556131008901002

[11] Hwang, C.S., Yang, H.S. and Hong, M.K. (1998) Detection of Human Papilloma Virus (HPV) in Sinonasal Inverted Papillomas Using Polymerase Chain Reaction (PCR). American Journal of Rhinology, 12, 363-366. https://doi.org/10.2500/105065898780182499

[12] Kraft, M., Simmen, D., Casas, R. and Pfaltz, M. (2001) Significance of Human Papillomavirus in Sinonasal Papillomas. The Journal of Laryngology \& Otology, 115, 709-714. https://doi.org/10.1258/0022215011908955

[13] Mohajeri, S., Lai, C., Purgina, B., Almutairi, D., Baghai, T., Dimitroulakos, J. and Kilty, S. (2018) Human Papillomavirus: An Unlikely Etiologic Factor in Sinonasal Inverted Papilloma. The Laryngoscope, 128, 2443-2447. https://doi.org/10.1002/lary.27207

[14] Lee, H.J. and Kim, J.W. (2013) Immunohistochemical Study on the Expression of Matrix Metalloproteinase 2 and High-Risk Human Papilloma Virus in the Malignant Progression of Papillomas. Journal of the Korean Association of Oral and Maxillofacial Surgeons, 39, 224-230. https://doi.org/10.5125/jkaoms.2013.39.5.224

[15] Dager, A.M., Rolland, D.C.M., McHugh, J.B., Betz, B.L., Murga-Zamalloa, C., Carey, T.E., Marentette, L.J., Hermsen, M.A., DuRoss, K.E., Lim, M.S., Elenitoba-Johnson, K.S.J. and Brown, N.A. (2015) High-Frequency Targetable EGFR Mutations in Sinonasal Squamous Cell Carcinomas Arising from Inverted Sinonasal Papilloma. Cancer Research, 75, 2600-2606. https://doi.org/10.1158/0008-5472.CAN-15-0340

[16] Scheel, A., Lin, G.C., McHugh, J.B., Komarck, C.M., Walline, H.M., Prince, M.E., Zacharek, M.A. and Carey, T.E. (2015) Human Papillomavirus Infection and Biomarkers in Sinonasal Inverted Papillomas: Clinical Significance and Molecular Mechanisms. International Forum of Allergy \& Rhinology, 5, 701-707.

https://doi.org/10.1002/alr.21524

[17] Nowosielska-Grygiel, J., Pietkiewicz, P., Owczarek, K., Olszewski, J. and Miłoński, J. (2017) Diagnosis and Treatment of Nasal and Paranasal Inverted Papillomas-Epidemiology and Own Experience. Polish Journal of Otolaryngology, 71, 27-32. https://doi.org/10.5604/01.3001.0010.7195

[18] Lewis, J.S., Westra, W.H., Thompson, L.D., Barnes, L., Cardesa, A., Hunt, J.L., Williams, M.D., Slootweg, P.J., Triantafyllou, A., Woolgar, J.A., Devaney, K.O., Rinaldo, A. and Ferlito, A. (2014) The Sinonasal Tract: Another Potential "Hot Spot" for Carcinomas with Transcriptionally-Active Human Papillomavirus. Head and Neck Pathology, 8, 241-249. https://doi.org/10.1007/s12105-013-0514-4

[19] Hong, S.L., Kim, B.H., Lee, J.H., Cho, K.S. and Roh, H.J. (2013) Smoking and Malignancy in Sinonasal Inverted Papilloma. The Laryngoscope, 123, 1087-1091. https://doi.org/10.1002/lary.23876

[20] Bhalla, R.K. and Wright, E.D. (2009) Predicting the Site of Attachment of Sinonasal 
Inverted Papilloma. Rhinology, 47, 345-348. https://doi.org/10.4193/Rhin08.229

[21] Roland, D.E. (2009) Inverted Papilloma of the Nose and Paranasal Sinuses in Childhood and Adolescence. The Laryngoscope, 95, 17-23. https://doi.org/10.1288/00005537-198501000-00007

[22] Krouse, J.H. (2000) Development of a Staging System for Inverted Papilloma. The Laryngoscope, 110, 965-968. https://doi.org/10.1097/00005537-200006000-00015

[23] Vrabec, D.P. (1994) The Inverted Schneiderian Papilloma: A Clinical and Pathological Study. The Laryngoscope, 104, 582-605.

https://doi.org/10.1002/lary.5541040513

[24] Calcaterra, T.C., Thompson, J.W. and Paglia, D.E. (1980) Inverting Papillomas of the Nose and Paranasal Sinuses. The Laryngoscope, 90, 53-60. https://doi.org/10.1288/00005537-198001000-00006

[25] Baruah, P. and Deka, R.C. (2003) Endoscopic Management of Inverted Papillomas of the Nose and Paranasal Sinuses. Ear, Nose \& Throat Journal, 82, 317-320. https://doi.org/10.1177/014556130308200416

[26] Kraft, M., Simmen, D., Kaufmann, T. and Holzmann, D. (2003) Longterm Results of Endonasal Sinus Surgery in Sinonasal Papillomas. The Laryngoscope, 113, 1541-1547. https://doi.org/10.1097/00005537-200309000-00025

[27] Peng, P. and Har-El, G. (2006) Management of Inverted Papillomas of the Nose and Paranasal Sinuses. American Journal of Otolaryngology, 27, 233-237. https://doi.org/10.1016/j.amjoto.2005.11.005

[28] Thapa, N. and Pradhan, B. (2012) Sinonasal Inverted Papilloma. Journal of Institute of Medicine, 34, 10-13. https://doi.org/10.3126/jiom.v34i2.9044

[29] Busquets, J.M. and Hwang, P.H. (2006) Endoscopic Resection of Sinonasal Inverted Papilloma: A Meta Analysis. Otolaryngology_Head and Neck Surgery, 134, 476-482. https://doi.org/10.1016/j.otohns.2005.11.038

[30] Govindaraj, S. and Wang, H. (2014) Does Human Papilloma Virus Play a Role in Sinonasal Inverted Papilloma? Current Opinion in Otolaryngology \& Head and Neck Surgery, 22, 47-51. https://doi.org/10.1097/MOO.0000000000000017

[31] Wang, X.T., Li, P., Wei, X.Q., Wang, H.B., Pang, W.H., Li, B., Zhang, E.P. and Shi, G.G. (2013) Factors Affecting Recurrence of Sinonasal Inverted Papilloma. European Archives of Oto-Rhino-Laryngology, 270, 1349-1353. https://doi.org/10.1007/s00405-012-2216-Z

[32] Chee, L.W. and Sethi, D.S. (1999) The Endoscopic Management of Sinonasal Inverted Papillomas. Clinical Otolaryngology and Allied Sciences, 24, 61-66. https://doi.org/10.1046/j.1365-2273.1999.00222.x

[33] Lee, J.T., Bhuta, S., Lufkin, R. and Castro, D.J. (2003) Isolated Inverting Papilloma of the Sphenoid Sinus. The Laryngoscope, 113, 41-44. https://doi.org/10.1097/00005537-200301000-00008

[34] Lisan, Q., Laccourreye, O. and Bonfils, P. (2017) Sinonasal Inverted Papilloma: Risk Factors for Local Recurrence after Surgical Resection. Annals of Otology, Rhinology \& Laryngology, 126, 498-504. https://doi.org/10.1177/0003489417705671

[35] Lund, V.J., Stammberger, H., et al. (2010) European Rhinologic Society Advisory Board on Endoscopic Techniques in the Management of Nose, Paranasal Sinus and Skull Base. Rhinology. Supplement, 22, 1-143.

[36] Coutinho, G., Marques, J., Leal, M., Spratley, J., Fernandes, M.S. and Santos, M. (2020) Surgical Outcomes of Sinonasal Inverted Papilloma: A 17 Year Review. Brazilian Journal of Otorhinolaryngology, 86, 315-320. 
https://doi.org/10.1016/j.bjorl.2018.12.011

[37] Kim, D.Y., Hong, S.L., Lee, C.H., Jin, H.R., Kang, J.M. and Lee, B.J. (2012) Inverted Papilloma of the Nasal Cavity and Paranasal Sinuses: A Korean Multicenter Study. Laryngoscope, 122, 487-494. https://doi.org/10.1002/lary.22495

[38] Wolfe, S.G., Schlosser, R.J., Bolger, W.E., Lanza, D.C. and Kennedy, D.W. (2004) Endoscopic and Endoscope Assisted Resections of Inverted Sinonasal Papillomas. Otolaryngology_Head and Neck Surgery, 131, 174-179. https://doi.org/10.1016/j.otohns.2004.05.011

[39] Thorp, M., Oyarzabal Amigo, M., Du Plessis, J. and Sellars, S. (2001) Inverted Papilloma: A Review of 53 Cases. The Laryngoscope, 111, 1401-1405. https://doi.org/10.1097/00005537-200108000-00016

[40] Cansz, H., Tahamiler, R., Yener, M., Acoglu, E. and Guvenc, M.G. (2008) Modified Midfacial Degloving Approach for Sinonasal Tumors. Journal of Craniofacial Surgery, 19, 1518-1522. https://doi.org/10.1097/SCS.0b013e31818b2ceb

[41] Lin, G.C., Akkina, S., Chinn, S., Prince, M.E., McHugh, J.B., Carey, T. and Zacharek, M.A. (2014) Sinonasal Inverted Papilloma: Prognostic Factors with Emphasis on Resection Margins. Journal of Neurological Surgery Part B: Skull Base, 75, 140 146. https://doi.org/10.1055/s-0033-1363169

[42] Gras-Cabrerizo, J.R., Montserrat-Gili, J.R., Massegur-Solench, H., León-Vintró, X., De Juan, J. and Fabra-Llopis, J.M. (2010) Management of Sinonasal Inverted Papillomas and Comparison of Classification Staging Systems. American Journal of Rhinology \& Allergy, 24, 66-69. https://doi.org/10.2500/ajra.2010.24.3421

[43] Tomazic, P.V., Hubmann, F. and Stammberger, H. (2015) Problem of High Recurrence Rate in Endoscopic Revision Surgery for Inverted Papilloma. Laryngorhinootologie, 94, 447-450. https://doi.org/10.1055/s-0034-1385946

[44] Re, M., Gioacchini, F.M., Bajraktari, A., Tomasetti, M., Kaleci, S., Rubini, C., Bertini, A., Magliulo, G. and Pasquini, E. (2017) Malignant Transformation of Sinonasal Inverted Papilloma and Related Genetic Alterations: A Systematic Review. European Archives of Oto-Rhino-Laryngology, 274, 2991-3000. https://doi.org/10.1007/s00405-017-4571-2

[45] Udager, A.M., McHugh, J.B., Goudsmit, C.M., Weigelin, H.C., Lim, M.S., Elenitoba-Johnson, K.S.J., Betz, B.L., Carey, T.E. and Brown, N.A. (2018) Human Papillomavirus (HPV) and Somatic EGFR Mutations Are Essential, Mutually Exclusive Oncogenic Mechanisms for Inverted Sinonasal Papillomas and Associated Sinonasal Squamous Cell Carcinomas. Annals of Oncology, 29, 466-471. https://doi.org/10.1093/annonc/mdx736

[46] Sahnane, N., Ottini, G., Turri-Zanoni, M., Furlan, D., Battaglia, P., Karligkiotis, A., Albeni, C., Cerutti, R., Mura, E. and Chiaravalli, A.M. (2019) Comprehensive Analysis of HPV Infection, EGFR Exon 20 Mutations and LINE1 Hypomethylation as Risk Factors for Malignant Transformation of Sinonasal-Inverted Papilloma to Squamous Cell Carcinoma. International Journal of Cancer, 144, 1313-1320. https://doi.org/10.1002/ijc.31971

[47] Moon, I.J., Lee, D,Y., Suh, M.W., Han, D.H., Kim, S.T., Min, Y.G., Lee, C.H. and Rhee, C.S. (2010) Cigarette Smoking Increases Risk of Recurrence for Sinonasal Inverted Papilloma. American Journal of Rhinology \& Allergy, 24, 325-329. https://doi.org/10.2500/ajra.2010.24.3510

[48] Keleş, N., Erdamar, B., Kaur, A. and Değer, K. (2003) p21, p53, and p27 Kip1 Alterations in Benign and Malignant Tumors of Sinonasal Epithelium. Otolaryngology-Head and Neck Surgery, 129, 77-84. 
https://doi.org/10.1016/S0194-5998(03)00520-5

[49] Wormald, P.J., Ooi, E., van Hasselt, C.A. and Nair, S. (2003) Endoscopic Removal of Sinonasal Inverted Papilloma Including Endoscopic Medial Maxillectomy. The Laryngoscope, 113, 867-873. https://doi.org/10.1097/00005537-200305000-00017 